Journal of

Online and Distance

Learning

(JODL)

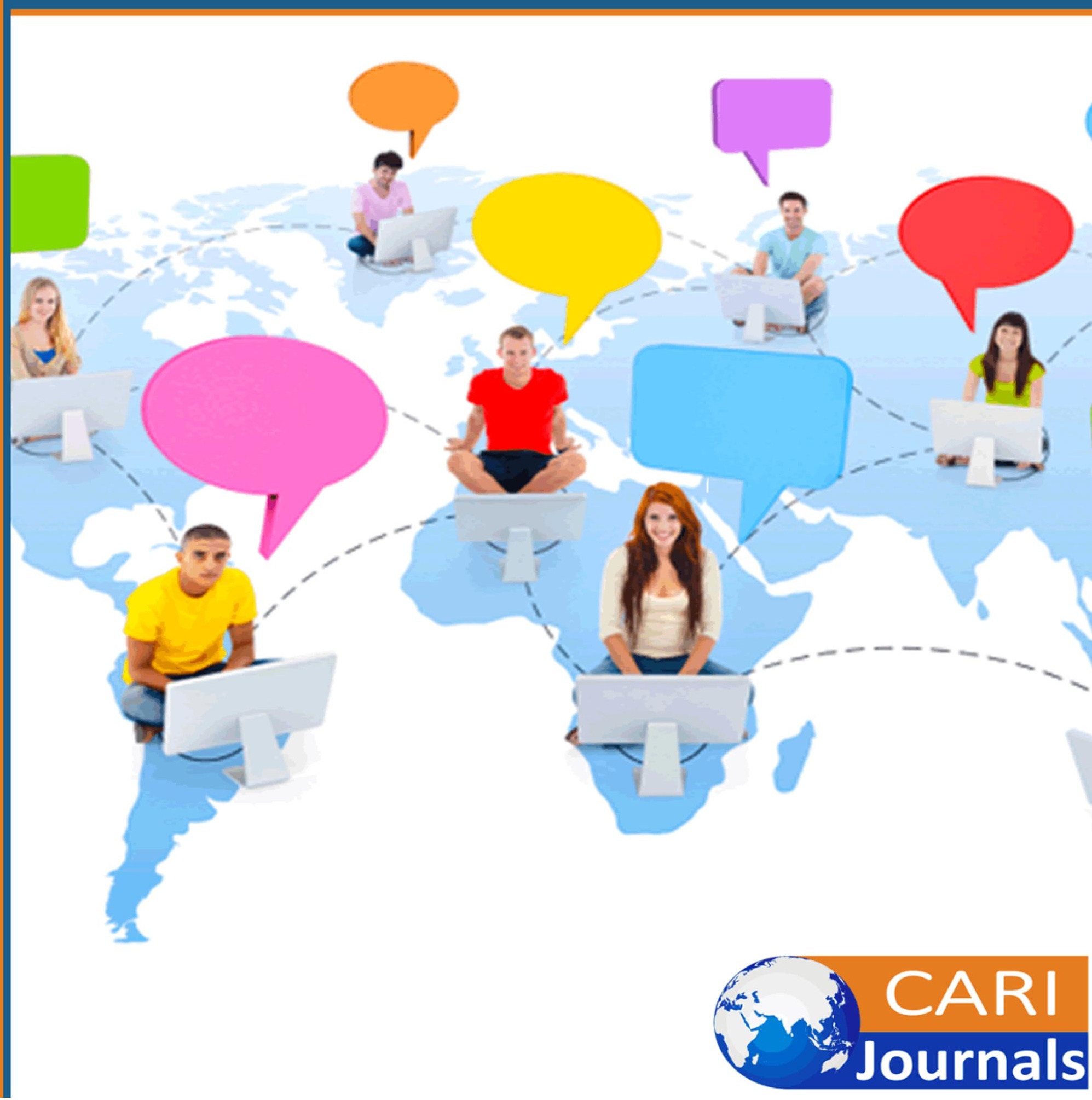




\title{
THE ADVANTAGE OF ADOPTION OF OPEN DISTANCE AND E-LEARNING TO INCREASE ACCESS TO FEMALE HIGHER EDUCATION.
}

\author{
Alfred Mwangi, \\ Department of Education, University of Nairobi \\ *Corresponding author's Email: alfred@cari.org
}

\begin{abstract}
Purpose: A highly educated woman is viewed as rude, uncooperative and unable to manage house work. These perceptions are said to discourage some female and their parents from pursuing higher education in marginal areas. The general objective of the study was to establish advantage of adoption of Open Distance and e-Learning to increase access to female in higher education.
\end{abstract}

Methodology: The paper used a desk study review methodology where relevant empirical literature was reviewed to identify main themes and to extract knowledge gaps.

Findings: The study recommends that is a need for pursuing policies and programs to develop Information and Communication Technology as well as Open and Distance Education to wide access to quality educational opportunities. There is general recognition of the potential for Open Distance and e-Learning to meet the needs of some groups of women. This study proposes the development of Information and Communication Technology and Open Distance and e-Learning policies to exploit the advantages of the mass media while at the same time putting in place the development of supportive electronic networks. Also, a strong national framework is required to support a national quality assurance network in order to guide student assessment systems at all levels of Open Distance and e-Learning.

Recommendations: The study recommends that is a need for pursuing policies and programmes to develop Information and Communication Technology as well as Open and Distance Education to wide access to quality educational opportunities. There is general recognition of the potential for Open Distance and e-Learning to meet the needs of some groups of women. This study proposes the development of Information and Communication Technology and Open Distance and e-Learning policies to exploit the advantages of the mass media while at the same time putting in place the development of supportive electronic networks. Also, a strong national framework is required to support a national quality assurance network in order to guide student assessment systems at all levels of Open Distance and e-Learning

Keywords: advantage, adoption, Open Distance, e-Learning, increase access, female, higher education 
Journal of Online and Distance Learning

Vol.1, Issue No.1, pp 1 - 13, 2021

$\underline{\text { www.carijournals.org }}$

\subsection{INTRODUCTION}

\subsection{Background of the Study}

Most University e-Learning programmes have been designed to increase access to higher education, especially for non-traditional students. In a recent survey on the 4 importance of various goals to institutions' distance education program (a high proportion of which use online technology as a primary or supporting medium of instruction), two out of three United States of America fouryear public institutions indicated that increasing student access was a very important goal; either by "making courses available at convenient locations" (72\%), or by "reducing time constraints for course taking" (66\%), (Demuyakor, 2020). The corresponding figures for four-year private institutions were also high (65\% and $61 \%$ respectively). In Europe, as well, there is abundant evidence to show that widening access to their programmes - and to their related academic resources - is an important objective of many university e-learning strategies; reaching new groups of students (women and other marginalised groups) is an additional and closely related goal (UNESCO, 2000). According to (Demuyakor, 2020), Open and Distance Learning offers opportunities for countries to meet the new and changing demands for education and training. Open and Distance Learning is both complementary and under certain circumstances an appropriate substitute for the face-to-face methods that still dominate most educational systems. The advantages of Open and Distance Learning are seen more in terms of the learner through more freedom of access, and thereby a wider range of opportunities for learning and qualification. The barriers that may be overcome by distance learning include not only geographical distance, but also other confining circumstances, such as personal constraints, cultural and social barriers and lack of educational infrastructure (Ali, 2020).

For the student, it is often a cheaper alternative to pursuing a course through conventional methods. Since many people cannot afford to leave their work in order to study, it is important that distance education and training may be combined with work. Distance and Open learning may also mean a more learner centred approach, allowing greater flexibility and choice of content as well as more personal organization of the learning programme (UNESCO 2002). Various studies have argued that the universalization of education and its worldwide acceptance as a continuous or lifelong undertaking, coupled with concerns about educational access and equity (Zhu, 2020) as well as the prevailing level of poverty, necessitate the use of various education delivery approaches to enable all citizens to benefit from this public good.

The conventional system caters for the needs of full-time learners from a specific age group enrolled in recognized institutions of learning at various levels of the education system: primary, secondary and tertiary. The requirements of such a system, usually determined by the relevant school/university boards, largely excludes many people outside traditional school-going age groups, those who are unable to fulfil essential eligibility requirements, and those who need education and training to gain competence in jobs and upgrading of their qualifications and training (Mitra,2020). In the conventional approach the learner has to be on campus, to register as a fulltime student and to attend face-to-face lectures. Open and Distance Learning in this respect would be more appropriate to marginal populations, especially women, who in certain communities are 
limited by culture, poverty and tradition to access regular higher education institutions. Women face challenges of multiple roles that may limit their ability to access traditional mediums of higher education that may mean leaving work, home, or family. Wahab (2020) argues that men constitute the first and underlying cause of gender (and perhaps every other form of) inequality. "it has become the prevailing custom in many societies that the male, gradually but determinedly acquired and retained decision within the family and other institutes of the society". Making decisions in such private and public matters definitely translates into holding and retaining the power to control most affairs. And little surprise, such decisions of cause, would always be more beneficial to the male. Kerres (2020) further argues that women, no matter how educated, do not belong to the Boys'/Men's clubs, where important information is shared and crucial decisions are made. Most of these decisions may result in the marginalization of women. Studies by Hochschild (1989), involving research on women's work and family life, introduced the idea of the 'second shift', this being the home shift that women do following formal paid employment. This 'shift' involves tasks traditionally undertaken by women linked to family and community, including housework, and childcare. The American Association of University Women (AAUW) believes that education forms a 'third shift', as more and more women see education as key to future opportunity and economic wellbeing and are embarking on distance education, adding study and research to their other roles. While studies by Hochschild and later by AAUW are based on research undertaken in the United States of America, their findings are relatively universally applicable. Due to their multiple existing roles, women are particularly 'vulnerable to negative effects of adding a new role such as student to their already busy lives' ( Basilaila, 2020).

Open Distance and e-Learning as a strategy to broaden access to higher education, especially for marginalized populations, have been promoted worldwide, particularly in the last two decades. This has been mainly due to what has been perceived as the failure of the traditional higher education structures to recruit students in equal proportions from different socio-economic groups. Free and open societies should promote social mobility by developing talent in every social and ethnic group this is an issue which needs to be addressed by schools, universities, employers and governments (Brackstone 2012). It is important that higher education institutions design strategies to recruit students from a wider range of students, including those from ethnic minorities, who are underrepresented in higher education. According to Salmi and Bassert (2012), any society committed to promoting equity must ensure that their education system, including their tertiary education sector, is accessible to students from the broadest spectrum of underrepresented and traditionally-excluded groups. Salmi and Bassert (2012) argues that supporting the opportunity to seek the benefits affordable by tertiary education in an equitable manner is reasonable and important, as well as just, based on the widespread evidence of the many public and private benefits of attaining a college degree. On a broader level, the public, societal benefits accrued by having higher levels of education present in the workforce include lower unemployment rates, increased tax revenues, greater civic and volunteer participation and lessened dependency on social services. Studies on access to higher education show that, by 2009, most countries had made significant efforts to increase female participation in higher education (Salmi and Bassert, 2012). However, South Asia and Sub-Saharan Africa still had considerably fewer females enrolled in tertiary education in comparison to the proportion enrolled in other regions. 
Studies undertaken in developed countries show that women enthusiastically and successfully take advantage of e-learning opportunities. For example studies in North America, New Zealand, the United Kingdom and the Netherlands show that women outnumber men in enrolments in distance courses, ranging from $61 \%-78 \%$ in selected universities. Enrolment for women in some of the larger Open Distance and e-Learning institutions varied from $50 \%$ at the Open University in the United Kingdom, 54.7\% at UNED Spain and 38\% at the Open University in the Netherlands (Murphy ,2020).

areas, some socio-cultural factors confine women to the lower levels of education system. Early marriages, where younger girls (under $15 \mathrm{yrs}$ ) are often married off to older wealthy men in order to fetch a good dowry is a major factor behind girls' low performance, drop-out and withdrawal from school. Female genital mutilation (FGM) is another factor. There is also strong belief that once married, girls become part of another family and parental investment is lost (Sahu,2020). Thus lack of money is an excuse for reluctant parents and families to invest in the girls' education because they do not perceive the value of education for girls and also because of the socio-cultural perception about the role of women in society. The high status accorded to marriage and motherhood in many communities' impacts negatively on female participation in education (Kapasia, 2020).

\subsection{Statement of the Problem}

This study set out to find out whether a sponsored Open Distance and e-Learning as a mode of delivering higher education and as an intervention has a potential of broadening access of female students from Arid and Semi-Arid and marginal areas to universities in Kenya. These females usually face various barriers in their attempt to university education as has been already pointed out in this discussion. Kenyatta University Marsabit Open Distance and e-Learning Centre was established to address these limitations in two ways: One, to train female teachers at the university level who would then be role models to stimulate girls' education within the Arid and Semi-Arid regions. Two, to provide higher education within convenient environments for women from the pastoralist communities of the region. The study also sought to find out how Open Distance and e-Learning was designed and implemented to increase female access to and participation in higher education within the Arid and Semi-Arid areas.

\subsection{Objectives of the Study}

The general objective of the study was to establish the advantage of adoption of Open Distance and e-Learning to increase access to female in higher education.

\subsection{Justification and Significance of the Study}

The findings of the study were expected to contribute to the literature informing the practices of designing and implementing Open Distance and e-Learning to be suitable to women in marginal areas. This was in respect to designing Open Distance and e-Learning programme that address the socio-cultural, economic and infrastructural challenges which impede their access to and participation in higher education. The study provided information about the student support programme and improvements that could be made to address the specific and real needs of female 
students from marginalized areas. The study was to provide information on the challenges of adopting Open Distance and e-Learning in remote areas and provide recommendations of overcoming them. The study was to inform the potentials that Open Distance and e-Learning had in increasing female participation in university education and how these could be harnessed to increase female participation in higher education, thus bridging the gender and regional gap in university education.

\section{LITERATURE REVIEW}

\subsection{Theoretical review}

Two theories were found to be relevant in influence of socio economic factors on staple food production. The theories that were found to best inform the research constructs are Paradigm shift theory, (1962) and Social Feminist Theory (Adamson, 1988).

\subsubsection{Paradigm Shift Theory}

According to Kuhn T. (1962), scientific revolution occurs when scientist uncounted anomalies which cannot be explained by the universally accepted Paradigm within which scientific progress has thereto been made. While applying the concept of paradigm within social context in addressing issues of changing paradigm, process popularly called paradigm shift, Handa (2012) shows how the shift affects social institutions in order to meet social needs and bring the desired social change. In this study, the current institutional-based access to university education highly favours male students and females from metropolitan regions. These ones do not face many barriers in their access to higher education. To broaden access to female students from Arid and Semi-Arid regions, who face many barriers in their attempt to access university education, there is a need for a paradigm shift to Open Distance and eLearning. In this context, the study attempted to find out whether Open Distance and eLearning and using student centered approaches for women had any impact in increasing female participation in higher education. In this current shift, Open Distance and e-Learning and student-centred approaches puts 'other groups' (women, marginalized communities) as on the same footing with dominant groups (men and women from metropolitan regions). The inflexible admission, selection and entry requirements by Joint Admissions Board and on-campus admission have limited the access of women from Arid and Semi-Arid and marginalized communities to higher education. Thus, such has to be replaced by a flexible admission and selection programme which caters for learner's needs and constraints of time, space, resources and socio-economic disabilities faced by women. This will give these hundreds of Kenyan women hope or a chance to 25 juggle multiple roles in society while they continue learning. With Open Distance and e-Learning there will be a shift from face-to-face, teacherlearner approach where the learner is passive, communication is one way, and learner is not involved in development of knowledge. Hence, the paradigm shift would involve learner-instructor approach where the learner is active, communication is two way and the learner is involved in knowledge development, decision making on what to learn, how and when to learn. 
Journal of Online and Distance Learning

Vol.1, Issue No.1, pp 1 - 13, 2021

$\underline{\text { www.carijournals.org }}$

\subsubsection{Social Feminist Theory}

According to Adamson, Briskin and McPhail (1988), in Lekalgitele (2003), social feminist recognizes that the exploitation and oppression of women are rooted in the structure of patriarchal capitalism. They believed that sexualism is so deeply ingrained in the social relationships of this that a fundamental transformation was necessary to bring about social change. All theoretical perspectives in society strongly agree that culture does not merely mimic the past; it alters the present and transforms the future. Since in most remote marginal areas women are not empowered and lack economic control, they cannot make decisions as to whom in their society is to be educated. They are also restricted to move from their homes for long periods unaccompanied by their spouses or male guardians. Moreover, traditional campus-based mode of delivery of higher education has led to gender and regional inequality in access to higher education because of the oppression and exploitation of females in the 26 society by males through these cultural restrictions. Sponsored Open Distance and e-Learning as a mode of delivery of higher education will enable females' access higher education within their cultural set-up. This will empower them economically and, since they are participating in economic growth of the society, may end their exploitation and oppression by males. This could result into change in the educational trends in these societies, leading to gender and regional balance in education.

\subsection{Empirical Review}

Wanjiru, (2018) conducted a study that sought to examine determinants of how government online services are utilized in Kenya with a focus on National Transport and Safety Authority Nairobi. The researcher adopted the Technology Acceptance Model Theory (TAM) of Vankatesh and Bala (2008). This theory explained how users take time to accept and make use of any new technology at their disposal. The study used a qualitative and descriptive survey research design. The target population was the customers who come for services at NTSA, and the employees of NTSA headquarters located in Upperhill Nairobi County. The sampling method that was used was simple random sampling, while Questionnaires as well as Interview Schedules were prepared to collect information from the employees and the customers. The information collected were reported with descriptive statistics like percentages and frequencies, and presented using tables, graphs and piecharts. It was then analyzed using Statistical Package for Social Sciences SPSS which was a software package that was used for non-batched and logical batched statistical analysis. Qualitative data got from items which were open-ended were coded by grouping the same answers together and analyzed in accordance with the thematic areas of the study. The key patterns and themes in the answers were identified and analyzed to give the usefulness, adequacy and information consistency. Results presentations were inform of charts and tables. Regression analysis was applied to determine relationships between the independent and dependent variables. The study found that digital literacy has significant effect on utilization of online government services. The study also established that digital culture has a significant effect on utilization of online government services. Further, the study found that e-governance implementation has a significant effect on utilization of online government services. The study recommends that the government should educate the staffs on the importance of online digital platforms through provision of free training programs so as to encourage the usage of online government services. Therefore, the study 
recommends that the government should: enhance staffs' competency through conducting regular training seminars, allocate funds for purchasing modern digital equipment and maintenance of operating systems so as to facilitate implementation of e-governance. The study also recommends that the government should educate the staffs on the importance of online digital platforms through provision of free training programs so as to encourage the usage of online government services. Therefore, the study recommends that the government should provide digital tutorial guides for public utilization through mass media such as You-tube television channels and internet so as to enhance digital literacy among the customers. The study also recommends that the government should enhance public awareness on utilization of government online services through mass media such as radio, television and internet so as to improve on their service delivery. Further, the study recommends that the government should ensure availability of educative tutorials in relation to utilization of government online services through internet and social media such as Facebook, Twitter and what's up so as to improve on digital literacy among the general customers.

Laichena , (2017) conducted a study set out to ascertain the types of learner support services offered to open, distance and e-learning students as well as identify learner support services that the students and the administrators felt were essential for effective learning. The study also intended to establish the attitudes of the users of open, distance and e-learning programmes on the learner support services offered and identify the factors that influence learner support services offered in open, distance and e-learning programmes in selected public universities in Kenya. The study limited itself to fourth year students undertaking a bachelor's degree programme only. This study was guided by the systems approach model whereby the types of learner support services offered by an institution enhances the success of open, distance and e-learning programmes through provision of adequate learner support services. Literature reviewed on the categories of services such as teaching and learning needs, access of information and personal and social needs (independent variables) showed that they determine the overall satisfaction of learner support services (dependent variable) offered. The study adopted a descriptive survey design. Purposive sampling was used to select three public universities offering open, distance and e-learning programmes, namely Egerton University, Kenyatta University and the University of Nairobi. Further, purposive sampling method was also used to select three study regions where each of the three universities had a study centre. A sample size of 329 fourth year students in the selected universities was arrived at using tables instituted by Morgan and Krejcie (1970). Stratified sampling technique was used to get a representation of students from each university while convenience sampling was used to select the students at each study centre from each university. All the administrators (directors and coordinators) were used in the study. The study instruments (interview schedules and questionnaires) were constructed to help in data collection. The data collected was coded, analysed and tabulated using the SPSS version 20 programme. Results were presented in form of frequency distribution tables and graphs. The study established that students rated majority of learner support services offered by their institutions across the three universities as poor while the administrators indicated that the services offered were good. However, the students and the administrators were of the opinion that there were essential learner support services that were very necessary to open, distance and e-learning students. Further, there was a consensus by the students and the administrators that the services offered were necessary though 
they needed to be improved. Lastly, the study found out that the administrators were aware of the essential learner support services but were limited by other factors that were beyond their control. The study recommends that; institutions offering open, distance and e-learning programmes should constantly assess the value of learner support services offered by constantly seeking the students ${ }^{\text {ee }}$ opinion and offer few but essential learner support services that are of high quality, adequate, of good quality and satisfactory to the students.

Mbithi, (2013) conducted a survey of Open, Distance and Electronic Learning Mode in Kenyan Universities with a bias to Administration, Delivery and Evaluation functions. The study also considered involvement of some project management concepts in the running of ODeL programmes in Kenyan Universities. The study involved four Universities. The research design was descriptive and the respondents were selected using stratified random sampling. Closed and open questionnaires were distributed randomly to a representative sample of the population which was used to collect data. The data was then recorded and coded in Microsoft excel soft ware for analysis, interpretation and representation. The study found out that Kenyan Universities are providing ODeL students with most of the necessary support services in terms of content access, participation, orientations as well as creating a conducive environment for learning especially to those students who would have missed the access for higher education through face- to - face interaction. However, the study found out that Kenyan Universities lack some more effective interactive modem information technologies as compared to Open Universities from developed countries.

Sona,(2013) conducted a study that sought to establish the effect of IBT on the teaching methods, establish the effect of academic best practices on the learning culture and investigate the effect of IBT on policy formulation of Kenyatta University City Campus. The researcher used case study research design purposively selected 120 respondents. This comprised of 100 students selected from four departments, 10 administrators and 10 lecturers. Primary data was collected using selfadministered questionnaires. The collected quantitative data has been analysed using descriptive statistics. In addition, content analysis was used for qualitative data. To aid data analysis the researcher used the statistical package for social sciences (SPSS). The study found out that respondents preferred online materials and that internet had helped in reducing the duration for doing assignments, and internet has improved inter-campus sharing. Internet availability had also improved the quality of assignments and has improved the overall conceptualization of ideas and subjects by students. The respondents also used internet for academic research, social interactions, and games as well as for business purposes. The students also agreed that they spent more and unnecessary time on social websites, internet games than on academic research, students accessed and download the wrong materials from the university web access points, and students directly downloaded class assignments and presented them without their own input, since they found it is easier to download class assignments. Generally, the results indicate that internet use have had a negative effect on the learning and as well teaching within the City Campus. Internet also had influenced learning abilities of students by reducing class attendance by avoided lessons since they could easily access notes online, lack of in-depth research from different source (prefer internet) among other negative aspects. The respondents preferred online/distance and e-learning methods 
to traditional classroom lectures, indicating the need to respond to the new challenges and needs of the students by adopting internet based teaching methodologies. On whether the policy framework had been modified since the advent of internet based teaching and learning within the university education, the $50 \%$ the respondents agreed that it had been modified while the other $50 \%$ did not agree. The study also found out that plagiarism could not be stamped out with the advent of the internet based learning. The learning culture had also changed with the internet with students no longer appreciating classroom-setting lectures, nor hard copies of notes rather they would appreciate more the online notes and other online functionaries like submission of assignments through internet.

\subsection{Research gaps}

Geographical gap is a knowledge gap that considers, the untapped potential or missing/limited research literature, in the geographical area that has not yet been explored or is under-explored. For instance, Wanjiru , (2018) conducted a study that sought to examine determinants of how government online services are utilized in Kenya with a focus on National Transport and Safety Authority Nairobi. The researcher adopted the Technology Acceptance Model Theory (TAM) of Vankatesh and Bala (2008). This theory explained how users take time to accept and make use of any new technology at their disposal. The study used a qualitative and descriptive survey research design. The study also established that digital culture has a significant effect on utilization of online government services. Further, the study found that e-governance implementation has a significant effect on utilization of online government services. The study presented a geographical gap as it was done in Nairobi while our current study sought to establish the advantage of adoption of Open Distance and e-Learning to increase access to female in higher education.

Methodological gap is the gap that is presented as a result in limitations in the methods and techniques used in the research (explains the situation as it is, avoids bias, positivism, etc. Laichena , (2017) conducted a study set out to ascertain the types of learner support services offered to open, distance and e-learning students as well as identify learner support services that the students and the administrators felt were essential for effective learning. The study adopted a descriptive survey design. Purposive sampling was used to select three public universities offering open, distance and e-learning programmes, namely Egerton University, Kenyatta University and the University of Nairobi.The the study found out that the administrators were aware of the essential learner support services but were limited by other factors that were beyond their control. The study recommends that; institutions offering open, distance and e-learning programmes should constantly assess the value of learner support services offered by constantly seeking the students ${ }^{\text {ee }}$ opinion and offer few but essential learner support services that are of high quality, adequate, of good quality and satisfactory to the students. The study presented a methodological gap as it was subjected to descriptive research design while our current study adopted a desktop literature review method.

Conceptual gap arises because of some difference between the user's mental model of the application and how the application actually works. Mbithi, (2013) conducted a survey of Open, 
Distance and Electronic Learning Mode in Kenyan Universities with a bias to Administration, Delivery and Evaluation functions. The research design was descriptive and the respondents were selected using stratified random sampling. The study found out that Kenyan Universities lack some more effective interactive modem information technologies as compared to Open Universities from developed countries. The study presented a conceptual gap as it investigated a survey of Open, Distance and Electronic Learning Mode in Kenyan Universities with a bias to Administration, Delivery and Evaluation functions while our current study will focus on advantage of adoption of Open Distance and e-Learning to increase access to female in higher education.

\subsection{METHODOLOGY}

The study adopted a desktop literature review method (desk study). This involved an in-depth review of studies related to advantage of adoption of Open Distance and e-Learning to increase access to female in higher education. Three sorting stages were implemented on the subject under study in order to determine the viability of the subject for research. This is the first stage that comprised the initial identification of all articles that were based on advantage of adoption of Open Distance and e-Learning to increase access to female in higher education from various data bases. The search was done generally by searching the articles in the article title, abstract, keywords. A second search involved fully available publications on the subject on advantage of adoption of Open Distance and e-Learning to increase access to female in higher education. The third step involved the selection of fully accessible publications. Reduction of the literature to only fully accessible publications yielded specificity and allowed the researcher to focus on advantage of adoption of Open Distance and e-Learning to increase access to female in higher education which was split into top key words. After an in-depth search into the top key words (advantage, adoption ,Open Distance, e-Learning, increase access, female ,higher education), the researcher arrived at 6 articles that were suitable for analysis. The 5 articles were findings from Wanjiru , (2018) conducted a study that sought to examine determinants of how government online services are utilized in Kenya with a focus on National Transport and Safety Authority Nairobi. The researcher adopted the Technology Acceptance Model Theory (TAM) of Vankatesh and Bala (2008). This theory explained how users take time to accept and make use of any new technology at their disposal. The study used a qualitative and descriptive survey research design. The study also established that digital culture has a significant effect on utilization of online government services. Further, the study found that e-governance implementation has a significant effect on utilization of online government services.

Laichena , (2017) conducted a study set out to ascertain the types of learner support services offered to open, distance and e-learning students as well as identify learner support services that the students and the administrators felt were essential for effective learning. The study adopted a descriptive survey design. Purposive sampling was used to select three public universities offering open, distance and e-learning programmes, namely Egerton University, Kenyatta University and the University of Nairobi. The the study found out that the administrators were aware of the essential learner support services but were limited by other factors that were beyond their control. The study recommends that; institutions offering open, distance and e-learning programmes should 
constantly assess the value of learner support services offered by constantly seeking the studentse opinion and offer few but essential learner support services that are of high quality, adequate, of good quality and satisfactory to the students.

Mbithi, (2013) conducted a survey of Open, Distance and Electronic Learning Mode in Kenyan Universities with a bias to Administration, Delivery and Evaluation functions. The research design was descriptive and the respondents were selected using stratified random sampling. The study found out that Kenyan Universities lack some more effective interactive modem information technologies as compared to Open Universities from developed countries.

Sona,(2013) conducted a study that sought to establish the effect of IBT on the teaching methods, establish the effect of academic best practices on the learning culture and investigate the effect of IBT on policy formulation of Kenyatta University City Campus. The researcher used case study research design purposively selected 120 respondents. This comprised of 100 students selected from four departments, 10 administrators and 10 lecturers. Primary data was collected using selfadministered questionnaires. The results indicate that internet use have had a negative effect on the learning and as well teaching within the City Campus. Internet also had influenced learning abilities of students by reducing class attendance by avoided lessons since they could easily access notes online, lack of in-depth research from different source (prefer internet) among other negative aspects.

\subsection{SUMMARY, CONCLUSION AND POLICY IMPLICATION FOR FURTHER STUDY}

\subsection{Summary}

Measures taken to increase access to higher education in Kenya, especially for female students and students from marginalized groups have hardly democratized or enhanced equity at this level. On the contrary, patterns of access to both public and private universities tend to reflect increasing regional, gender and socioeconomic differentiation in the country.

\subsection{Conclusion}

From the study findings, it is concluded that a sponsored Open Distance and e-Learning have a greater potential of broadening access to university education for female students from Arid and Semi-Arid and marginalized areas. This study also concludes that though the Kenyatta University Marsabit Centre was at a pilot phase, the concept was acceptable to both the students and the community. The fact that among the students who had registered were those who were already married indicated that Open Distance and e-Learning would address the cultural barrier in the community which restricted women generally. Even married women's mobility outside their homes in search of higher education depended on the permission of their husbands or male guardians. The fact that married women had enrolled showed acceptability from their husbands. However, in terms of actual implementation, the findings show that much needed to be done to address quality related concerns

\subsection{Recommendations}


The study recommends that is a need for pursuing policies and programmes to develop Information and Communication Technology as well as Open and Distance Education to wide access to quality educational opportunities. There is general recognition of the potential for Open Distance and eLearning to meet the needs of some groups of women. This study proposes the development of Information and Communication Technology and Open Distance and e-Learning policies to exploit the advantages of the mass media while at the same time putting in place the development of supportive electronic networks. Also, a strong national framework is required to support a national quality assurance network in order to guide student assessment systems at all levels of Open Distance and e-Learning

\section{REFERENCES}

Ali, W. (2020). Online and remote learning in higher education institutes: A necessity in light of COVID-19 pandemic. Higher Education Studies, 10(3), 16-25.

Ali, Wahab. "The Efficacy of Evolving Technology in Conceptualizing Pedagogy and Practice in Higher Education." Higher Education Studies 9, no. 2 (2019): 81-95.

Demuyakor, J. (2020). Coronavirus (COVID-19) and online learning in higher institutions of education: A survey of the perceptions of Ghanaian international students in China. Online Journal of Communication and Media Technologies, 10(3), e202018.

Kapasia, N., Paul, P., Roy, A., Saha, J., Zaveri, A., Mallick, R., ... \& Chouhan, P. (2020). Impact of lockdown on learning status of undergraduate and postgraduate students during COVID-19 pandemic in West Bengal, India. Children and Youth Services Review, 116, 105194.

Kerres, M. (2020). Against all odds: Education in Germany coping with Covid-19. Postdigital Science and Education, 2(3), 690-694.

Mbithi, B. M. (2013). Influence of financial transactions through mobile phones on the growth of Safaricom agents in Kisumu county, Kenya (Doctoral dissertation, University of Nairobi).

Mitra, S., \& Mitra, J. C. Education after covid-19 (real pandemic). : 2020, 187.

Murphy, M. P. (2020). COVID-19 and emergency eLearning: Consequences of the securitization of higher education for post-pandemic pedagogy. Contemporary Security Policy, 41(3), 492-505.

Oirere, G. G. Month: August 2018.

Sahu, P. (2020). Closure of universities due to coronavirus disease 2019 (COVID-19): impact on education and mental health of students and academic staff. Cureus, 12(4). 
WANJIRU, M. J. (2018). Determinants of utilization of government online services in kenya: case of national transport And safety authority nairobi (Doctoral dissertation, kenyatta university).

Zhu, X., \& Liu, J. (2020). Education in and after Covid-19: Immediate responses and long-term visions. Postdigital Science and Education, 2(3), 695-699. 